\title{
Type shifts and noun class changes under determination in Teop
}

\author{
Ulrike Mosel
}

\section{Introduction*}

This paper investigates the correlations between the four conceptual types of nouns identified by Löbner (2011) and the three noun classes of the Oceanic language Teop ${ }^{1}$ and their subclasses. Both kinds of classification make use of the distinctive binary features $[ \pm$ unique] and [ \pm relational], abbreviated as $[ \pm \mathrm{U}]$ and $[ \pm \mathrm{R}]$. But the Teop noun class system does not fully match with the system of conceptual types. Some mismatches can be attributed to the semantic feature [ \pm human] that overrules the features $[ \pm \mathrm{U}]$ and $[ \pm \mathrm{R}]$; others may perhaps originate from historical developments of the language.

The conceptual lexical types of nouns, here exemplified by Teop examples, are as follows:

1. individual nouns, i. e. inherently unique non-relational nouns $[+\mathrm{U},-\mathrm{R}]$, e. g. Naphtali, Ruth, iaa 'Mum', sivao 'moon', Teapu 'Teop Island';

2. functional nouns, i. e. inherently unique relational noun $[+\mathrm{U},+\mathrm{R}]$, e. g. tama'father', kahoo 'head';

3. relational nouns, i. e. inherently relational non-unique nouns $[-U,+R]$, e.g. kuri- 'hand', vavina- 'sibling of the opposite sex';

* I am grateful to Sebastian Löbner and his research team for introducing me to their inspiring semantic theory, the Volkswagenstiftung who funded the Teop Language Documentation project from 2000 to 2007, and the Teop speakers who taught me their language. Many thanks also to the two anonymous reviewers who helped me to avoid shortcomings. The responsibility for all remaining errors rests with me.

1 For a more detailed classification see Ross (1988: 251-253). 
4. sortal nouns, i. e. inherently non-unique non-relational nouns [-U, - R], e.g. siisia 'teacher', moon 'woman', naono 'tree'.

The three Teop noun classes are formally distinguished by three sets of articles in unmarked NP constructions. As the forms of these articles are e/bene, a/bona, and o/bono (see Table 1 ), the noun classes are simply called the e-, the a- and the o-classes.

In NP constructions, determiners may change the head noun's inherent conceptual type when, for example, a sortal noun is determined by an anaphoric demonstrative and thus unequivocally refers to an individual concept. Modes of determination that lead to a conceptual type shift are classified as incongruent determinations and those that don't as congruent determinations (Löbner 2011: §5).

In Teop, one congruent mode of determination is, for example, the inalienable possessive construction of a unique body part term (1).

(1) kahoo-na =e

ART2.sG head-3sG.POSS =3sG.PRON

'its head' (Hel_13RG.009)

In this construction, the body part term belongs to the a-class. But when it is used without the possessive determiner and consequently becomes a non-relational sortal noun, it is assigned to the o-class:

(2) paa ani bono kahoo

TAM eat OBJ.ART3.SG head

'(she) ate the head' (Ata_01R.081)

In order to explore the question to what extent the Teop noun classes and noun class changes can be related to conceptual types and type shifts, the subsequent sections of this paper are structured as follows: $\S 2$ describes the Teop article paradigm and compares the three Teop noun classes with the four conceptual types of nouns. $\S 3$ presents a brief overview of the structure of the NP, $\S 4$ deals with the distinction of definite and indefinite noun phrases, $\S 5$ with possessive constructions and $\S 6$ with the expression of plurality. The final section $\S 7$ gives a summary of Teop noun class changes and compares them with conceptual type shifts.

My analysis is based on the consistently growing Teop Language Documentation Corpus (Mosel \& Thiesen 2007) that is compiled in ELAN ${ }^{2}$ and consists of

2 http://tla.mpi.nl/tools/tla-tools/ 
spontaneously spoken narratives and descriptions (abbr. R), edited versions of the transcriptions (abbr. E) and written texts that were not derived from previous recordings (abbr. W).

\section{Teop articles and the classification of nouns}

The Teop articles form a multidimensional asymmetric paradigm that distinguishes three noun classes, singular and plural, objects and non-objects, and three referential categories:

\begin{tabular}{|c|c|c|c|c|c|c|c|}
\hline articles & \multicolumn{2}{|c|}{$e$-articles (ART1) } & \multicolumn{2}{|c|}{$a$-articles (ART2) } & \multicolumn{2}{|c|}{$o$-article (ART3) } & abbr. \\
\hline $\begin{array}{l}\text { specific basic } \\
\text { article }\end{array}$ & $e$ & ere & $a$ & $o$ & $o$ & $a$ & \\
\hline $\begin{array}{l}\text { specific object } \\
\text { article }\end{array}$ & $\begin{array}{l}\text { bone, } \\
\text { bene }\end{array}$ & $\begin{array}{l}\text { bere, } \\
\text { benere }\end{array}$ & bona & bono & bono & bona & OBJ.ART \\
\hline $\begin{array}{l}\text { non-specific } \\
\text { article }\end{array}$ & - & - & ta & to & to & $t a$ & NSPEC.ART \\
\hline $\begin{array}{l}\text { partitive } \\
\text { article }\end{array}$ & - & - & & & & & PART.ART \\
\hline
\end{tabular}

Table 1: The paradigm of Teop articles

The specific object articles are only used with non-topical objects in clauses with a third-person subject. If the subject refers to a speech act participant or if the object is the topic of the clause, it is marked by the basic article (for further information see Mosel 2010b and Mosel 2010a).

The remainder of this section analyses two NP constructions without any articles (§2.1), gives an overview of the Teop noun classes and the corresponding conceptual types of nouns ( $\$ 2.2$ ), and briefly describes the structure of the noun phrase (§2.3). Due to limitations in space, the use of the partitive article is not analysed in this paper.

\subsection{Nominal arguments and adverbials without articles}

NPs with an argument function are usually marked by an article, but in fast, spontaneous spoken language the article may be dropped with NPs in clauseinitial position. The article is obligatorily absent in vocative phrases with proper names and common nouns, e. g. 
(3) O Taguone! Nomaa a-re voosu!

$\operatorname{VOC}^{3}$ PN come 1PL.IN.PRON-CONSEC go.home

'Oh Taguone! Come, let's go home! Come quickly!' (Iar_02E(Eno).078)

(4) Si otei ean sa antee haa tea vaa- kuu anaa ...! DIM man 2sG.PRON NEG can NEG COMP CAUS- fall 1sG.OBJ.PRON

'Dear man, you cannot make me fall down (from the tree)!' (Gol_01R.006)

(5) Bua otei, havee to nao vo= am?

two man where REL go GOAL= 2PL.PRON

'(You) two boys, where are you going?' (Skae_03W.017)

This absence of an article can be understood as a reflection of the special pragmatic and syntactic status of vocatives. They are forms of address with unique $(3,4)$ or non-unique definite (5) reference and are syntactically independent linguistic units.

A second nominal construction that obligatorily lacks an article is the locative phrase (LP) that functions as an attribute or an adverbial and refers to a unique place. While in (6) the toponym Teapu heads an object NP, Teapu without an article is an adverbial LP (7):

(6) Naa varakaha $n i=a \quad$ Teapu 1sG.PRON leave APP =ART2.SG Teop.Island

'I left Teop Island ...' (Mah_01R.039)

(7) Enaa skul Teapu 1sG.Pron go.to.school Teop.Island

'I went to school on Teop Island ...' (Mah_01R.029)

In both clauses the reference of the toponym is inherently unique; the adverbial LP Teapu in (7) cannot be replaced by a prepositional phrase. Sortal nouns denoting places, however, can be used in LPs as well as in prepositional phrases. When vaan 'village', for example, heads an LP, it refers to the particular village where the speaker or the protagonist of the story lives (compare Löbner 2011: 284), whereas the prepositional phrase refers to some other village:

(8) Erau, me= paa nao vahaa vaan.

so and $4=$ TAM go again village

'And so, (she) went back to the village.' (Nan_03R.137)

3 The vocative particle and the articles o ART3.SG and ART2.PL are homonyms. 
Type shifts and noun class changes under determination in Teop

(9) Enam na sugunate =a vaan bona,...

1PL.EX.PRON TAM arrive PREP $=$ ART2.SG village ANA

'When we arrived in that village, ... (and they sent us to Ovovoipa in the area of Aita ...).' (Nan_01E.051)

While in (8) the unique reference of vaan 'to the village' is domain-defined, it is established by the anaphoric demonstrative bona in (9). Inherently unique LPs like Teapu in (7) cannot be specified by the anaphoric demonstrative.

\subsection{Noun classes and conceptual types}

On the basis of their article selection in simple singular noun phrases, Teop nouns can be classified into three noun classes. The affiliation of nouns to one of the three classes is, to some extent, semantically motivated; the affiliation to the eclass in particular is predictable, whereas there are some idiosyncrasies in the aand o-classes.

1. The e-class comprises highly individuated human nouns like proper names, inalienably possessed kinship terms, nouns referring to social roles that are unique within certain social institutions such as, for instance, suunano 'paramount chief of a clan', but also non-unique social role terms like siisia 'teacher' and subuava 'old woman', and domestic animal names, e.g. guu 'pig', toa 'chicken'.

2. The a-class consists of common nouns referring to human beings, e. g. moon 'woman', higher animals other than domestic animals, e. g. keusu 'rat', landmarks, e.g. vaan 'village', food, e.g. huun 'soup', and artefacts, e.g. nahu 'pot', and part-of-a-whole terms e. g. kahoo 'head', paka 'leaf'.

3. The o-class comprises common nouns referring to plants and things made of plant materials, e.g. naono 'tree', hoi 'basket', lower animals vihivihii 'jellyfish' and amorphous substances other than water or soup, e.g. butoo 'mud', fire and light, e.g. the loanword raama 'lamp', and periods of time, e. g. vinu 'year'.

Basic noun phrases are introduced by a specific article and function as arguments, complements of prepositions, and predicates. They are singular and not marked by the diminutive particle, a numeral, a plural marker or the indefiniteness marker. 


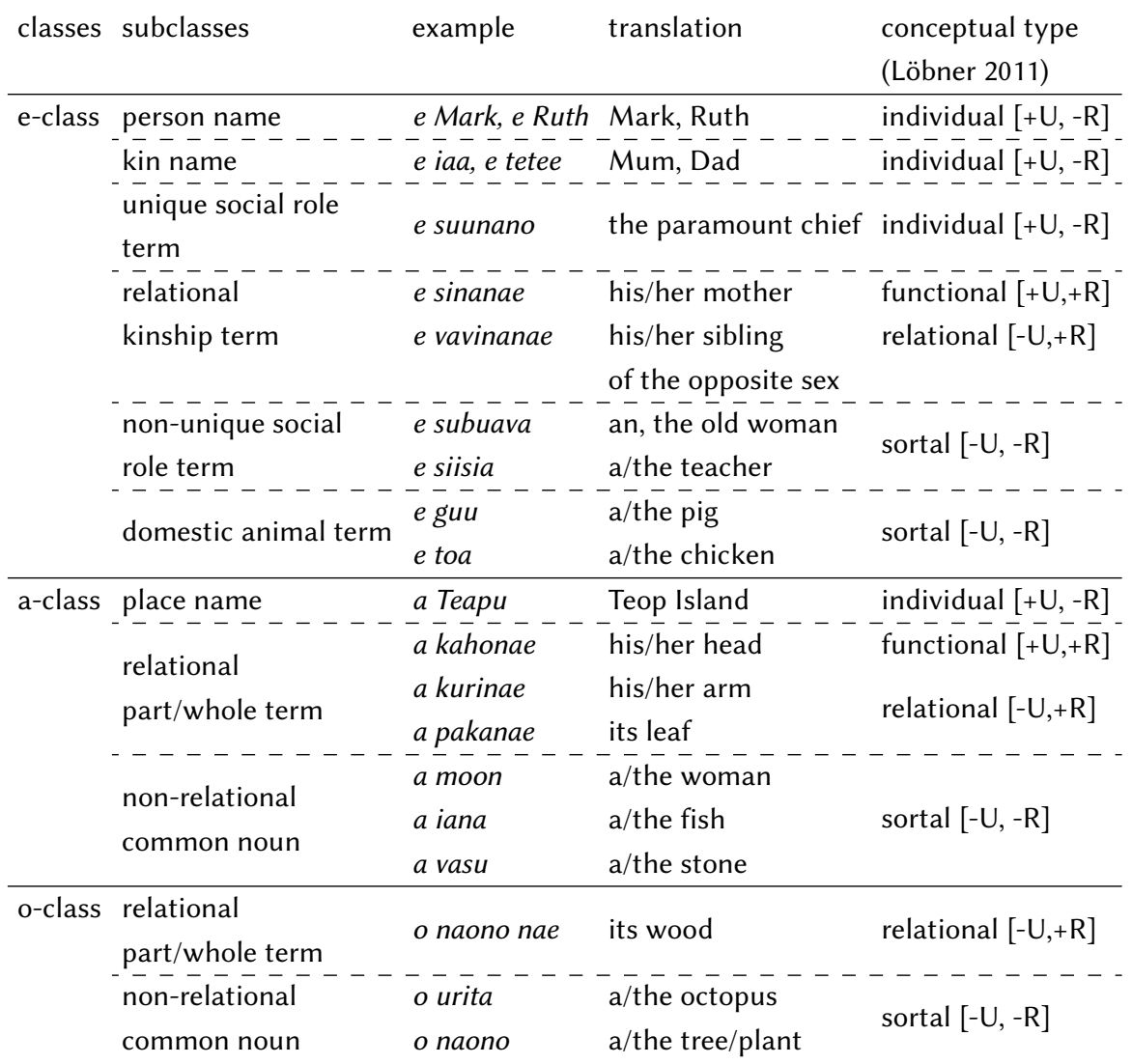

Table 2: Examples of the three Teop noun classes

Table 3 shows that there is no one-to-one relationship between conceptual types and noun classes in Teop. Individual nouns belong to the e-class if they refer to humans, but to the a-class if they refer to places. Secondly, in contrast to the $[+R]$ types of nouns, the $[+R]$ noun classes are not subclassified by the feature $[ \pm \mathrm{U}]$, but by the semantic feature [ \pm human], which does not figure in the system of conceptual types, but plays an important role in the lexical and grammatical structure of Teop. Thirdly, the sortal noun type is found in all Teop noun classes, but in the e-class it is restricted to a few common nouns referring to social roles of humans and to domestic animals.

The distinction between unique and non-unique social roles terms, e. g. suunano 'paramount chief' and subuava 'old woman' becomes evident in predicative 


\begin{tabular}{|c|c|c|}
\hline conceptual type & Teop noun class & \\
\hline \multirow[t]{2}{*}{ individual $[+\mathrm{U},-\mathrm{R}]$} & $\begin{array}{l}\text { e-class (names of persons, } \\
\text { unique social role terms) }\end{array}$ & [+human] \\
\hline & a-class (all place names) & [-human] \\
\hline \multirow[t]{2}{*}{ functional $[+U,+R]$} & e-class (kinship terms) & [+human] \\
\hline & a-class (part/whole terms) & [-human] \\
\hline \multirow[t]{3}{*}{ relational $[-\mathrm{U},+\mathrm{R}]$} & e-class (kinship terms) & [+human] \\
\hline & a-class (part/whole terms) & [-human] \\
\hline & o-class (only naono 'wood' attested) & [-human] \\
\hline \multirow[t]{4}{*}{ Sortal } & a-class (default) & {$[ \pm$ human $]$} \\
\hline & e-class (non-unique social roles) & [+human] \\
\hline & e-class (domestic animals) & [-human] \\
\hline & o-class (semantically restricted class) & [-human] \\
\hline
\end{tabular}

constructions ${ }^{4}$. While predicative nouns of the individual type are marked by the article $e$ to express identification and the article $a$ to express classification $(10,11)$, e-class nouns of the sortal type only take the article $a$ to express classification:

(10) Enaa e suunano

1SG.PRON ART1.SG paramount.chief

'I am the paramount chief (of the Nao Tahii clan).' (Mah_01R.067)

(11) Enaa a suunano.

1SG.PRON ART2.sG paramount.chief

'I am a paramount chief.' (Mah_03R.028)

(12) Enaa a subuava.

1SG.PRON ART2.SG old.woman

'I am an old woman.' (Sii_02R.559)

Although the change from the e-class to the a-class implies a type shift of the individual noun suunano 'paramount chief', the non-unique social-role term $s u b$ uava only changes the noun class, but not its conceptual type. This difference corresponds to the fact that only non-unique e-class nouns can enter the indefinite construction and may be determined by an anaphoric demonstrative (see $\S 4)$.

4 Note that Löbner (2011) does not deal with predicative NPs. 


\subsection{Specific vs. non-specific NPs}

The distinction between specific and non-specific articles is typical for Oceanic languages (Mosel \& Hovdhaugen 1992: 261-264). Specific NPs refer to particular entities and may be definite or indefinite. Thus the protagonist of a legend is often introduced by a specific NP which in English translates as an indefinite NP, and when it is mentioned a second time, it may have exactly the same form. Put differently, the type shift from an indefinite to a definite (pragmatically unique) NP is not overtly expressed.

(13) Nabunuu vai roho, na tei-tei roho a moon koa, long.time.ago DEM before TAM RED-stay before ART2.SG woman only a moon na tei-tei roho Teapu. ART2.SG woman TAM RED-stay before Teop.Island 'In former times, there was only one woman, the woman was staying on Teop Island.' (Pur_05E(Eno).002)

In contrast to specific NPs, an NP marked by the non-specific article refers to any item of the category denoted by the NP head. Non-specific NPs are typically found as subjects in negative existential clauses and as objects of the verb rake 'want':
Ae ahiki ta
taba ani ta
mataa.

and1 not.exist NSPEC.ART2.SG thing eat NSPEC.ART2.SG good

'And there was not any good food.' (Mor_01R.149)
Ean
na rake nom ta
taba?

2SG.PRON TAM want 2SG.IPFV NSPEC.ART2.SG thing

'Do you want anything?' (Vae_01E(Eno).163)

The negative existential construction is also used with proper names of persons and kinship terms, i. e. inherently unique nouns of the individual and the functional relational type:
(16) Ahiki ta
Gaagin ei!
not.exist NSPEC.ART2.SG PN here
'Gaagin is not here!' (lit. 'There isn't any Gaagin here!')
(Aro_05E(Eno).059) not.exist but NSPEC.ART2.SG mother-1PL.EX.POSS =1PL.EX.PRON 'However, none of our mothers (should see us)'
(17) Ahiki he ta sina-ma nam 
(lit. 'However, there isn't any mother of us') (Bua_01R.119)

The use of the non-specific a-class article $t a$ with unique human nouns that inherently belong to the e-class (see Table 1 and 2) clearly signals a noun class change as well as a type shift.

\section{The Teop noun phrase}

With the exceptions noted above in $\S 2.1$, NPs are introduced by an article and, in addition, may contain a number of pre-head and post-head modifiers (in the widest sense) as summarised in Table 4.

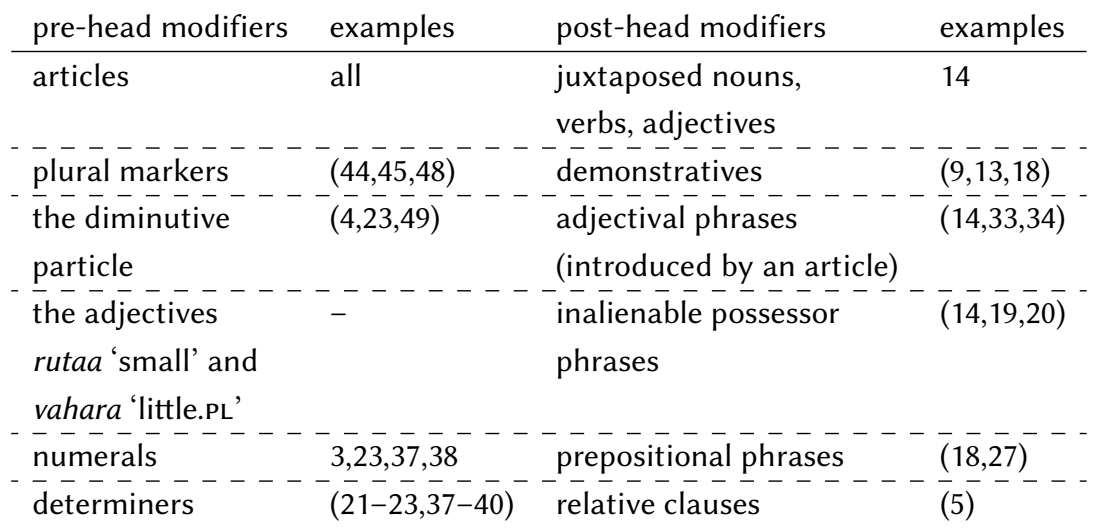

Table 4: Pre-head and post-head modifiers of the Teop NP

Alienable possessor NPs and pronouns are expressed by prepositional phrases introduced by the multipurpose preposition te PREP as in (18), whereas inalienable possessor NPs are marked on the possessee NP by a suffixed possessive marker (POss) that agrees in person and number with the possessor pronoun or NP.

$$
\begin{aligned}
& a \quad \text { tabaan te }=a \quad \text { iana bona } \\
& \text { ART2.SG food PREP }=\text { ART2.SG fish ANA } \\
& \text { 'the food of that fish' }(\text { Sii_11W.043 })^{5}
\end{aligned}
$$

(19) a kahoo- $n \quad=e \quad$ guu

ART2.SG head-3SG.POSS =ART1.SG pig

'the head of the pig' (Eno_10E.040)

5 In the Teop orthography the possessive marker and the clitic article or pronoun are often written as a separate word, e. g. kahoo nae, kahoo rio. 
(20)

$a \quad$ kahoo-ri $=0 \quad a b a$
ART2.SG head ${ }^{6}$-3PL.POSS = ART2.PL person
'the heads of human beings'(Aro 04R.041)

\section{Definite and indefinite NPs}

As shown in $\S 2.3$, Teop articles do not distinguish between definite and indefinite NPs. But there are two constructions that compensate for this lack of specification. Definiteness may be explicitly indicated by the anaphoric demonstrative bona ANA following the NP head and indefiniteness by the use of an indefinite determiner preceding the head of the NP.
Nabunuu a
peha roosuu na tei-tei roho. A
roosuu bona
long.ago ART2.SG INDEF giant TAM RED-stay before ART2.SG giant ANA
na antee nana tea taverete oraa ge...
TAM can 3SG.IPFV COMP1 change demon or
'Long ago there lived a giant. That giant was able to change into a demon or ...' (Sii_06RG.001-002)

The anaphoric demonstrative bona occurs with non-unique nouns of all noun classes and does not change the class affiliation of the noun:

\begin{tabular}{lll} 
& Translation & Reference \\
\hline e subuava bona & 'this old woman' & Aro_08(Eno).042 \\
e guu bona & 'this pig' & Kae_01R.043 \\
$\begin{array}{l}\text { a otei bona } \\
\text { o naono bona }\end{array}$ & 'this man' & Tah_05R.035 \\
& 'this tree' & Val_02R.078
\end{tabular}

Table 5: The anaphoric demonstrative: type shift without noun class shift

Another means of signalling the type shift of a sortal indefinite noun to a pragmatically unique sortal noun is a change from the a-class to the e-class. After the giant (a roosuu) has been introduced in the legend from which the example above (21) is taken, he is later on referred to by e roosuu 'the giant' (Sii_06RG.092). This kind of noun class change is common in legends and regularly found with animal names:

In contrast, the indefinite determiner marks a specific NP as indefinite, which yields a noun class change of non-unique e-class nouns:

\footnotetext{
6 Note that kahoo- is singular, which reflects the fact that it is a functional type of noun $[+\mathrm{U},+\mathrm{R}]$.
} 
Type shifts and noun class changes under determination in Teop

\begin{tabular}{lllll} 
sortal & \multicolumn{5}{c}{ individual } \\
\hline a bakubaku & Eno_11W.015 & e bakubaku & Ter_01R.064 & 'shark' \\
a manii & Sii_09W.025 & e manii & Vur_01E(Eno).02 & 'possum' \\
a moogee & Val_02R.034 & e moogee & Val_02R.034 & 'monkey'
\end{tabular}

Table 6: Type shift and noun class change with pragmatically unique animal names

(22) Na tei-tei roho a peha subuava, ...

TAM RED-stay before ART2.SG INDEF old.woman

'There was an old woman, ...' (Aro_07R. 001)

The indefinite determiner peha/peho is related to the cardinal numeral peha/peho 'one' and inflects for the noun class in the same way. But while the numeral peha/peho 'one' logically only occurs in NPs that refer to singular entities, the indefiniteness marker peha/peho INDEF is also found in NPs referring to more than one person or thing, which justifies our distinction between the numeral and the indefiniteness marker.

$$
\begin{aligned}
& \text { a peha bua si beiko } \\
& \text { ART2.SG }{ }^{7} \text { INDEF two DIM child } \\
& \text { 'a couple of little children' (Mui_01CE.019) }
\end{aligned}
$$

\section{Possessive constructions}

There are two kinds of possessor constructions in Teop, the inalienable and the alienable construction. While in inalienable constructions the first person singular possessor is simply formed by a pronominal suffix, all other possessors are indexed on the head noun by a suffix (POss) that inflects for person and number and agrees with the possessor pronoun or NP.

a hena-naa

ART2.SG name-1SG.PRON

'my name'

(25) $e \quad$ sina-na=e

ART1.SG mother=3SG.POSS-3SG.PRON

'his mother' (Aro_02R.004)

7 NPs determined by cardinal numerals are grammatically singular (see $§ 6.1$ ). 
(26)

$$
\begin{aligned}
& e \quad \text { sina-n }=a \quad \text { beiko } \\
& \text { ART1.SG mother-3sG.POSs =ART2.sG child } \\
& \text { 'the child's mother'(Aro_06R.035) }
\end{aligned}
$$

The alienable possessor construction is a prepositional phrase that is introduced by the multipurpose preposition te 'in, to, of'. It is typically found with a- and o-class nouns denoting things whose possession is controlled by the possessor referent. The alienable possessor construction does not change the noun class, merely the conceptual type from a sortal concept to a pragmatically unique concept.

$$
\begin{aligned}
& o \quad \text { sinivi te }=a n \\
& \text { ART3.SG canoe PREP }=2 \text { SG.PRON } \\
& \text { 'your canoe' (Sii_06RG.303) }
\end{aligned}
$$

Nouns that obligatorily enter inalienable constructions are grammatically and semantically relational nouns, but not all nouns that are semantically relational are grammatically relational, e. g. keara 'sibling of the same sex' (see §5.1).

\subsection{Possessive constructions of e-class nouns and type shifts}

Person names differ from all other e-class nouns in that they do not enter any possessive construction, whereas the other e-class nouns enter alienable or inalienable constructions and can be subclassified accordingly.

As shown in Table 2 and Table 7, there are two kinds of expression for kinship: the so-called kin names and the grammatically relational kinship terms. Kin names behave like person names in that they never occur in plural constructions and can be used as vocatives, whereas kinship terms can be pluralised (see §6.3), but are not used as vocatives.

(28) $O$ iaa! $O$ tetee! Sovee rakaha me= am paa mate kahi anaa? voc Mum voc Dad why indeed and4= 2PL TAM die from 1sG.OBJ.PRON 'Mum! Dad! Why indeed did you both die leaving me behind?'

(Sha_01E(Eno).029)

Secondly, speakers exclusively use the kin name when speaking about their own mother, father or grandparent, though mostly without a possessor, whereas for a third person's mother, father or grandparent the relational kinship term is preferred, which also explains why only kin names are found in the vocative construction (see § 2.1). Thirdly, kin names are grammatically non-relational, but in 
contrast to person names they may be modified by an alienable possessor construction. Table 8 shows the frequencies of the kin name iaa 'Mum' without and with possessors and the corresponding constructions of the kinship term sina'mother'.

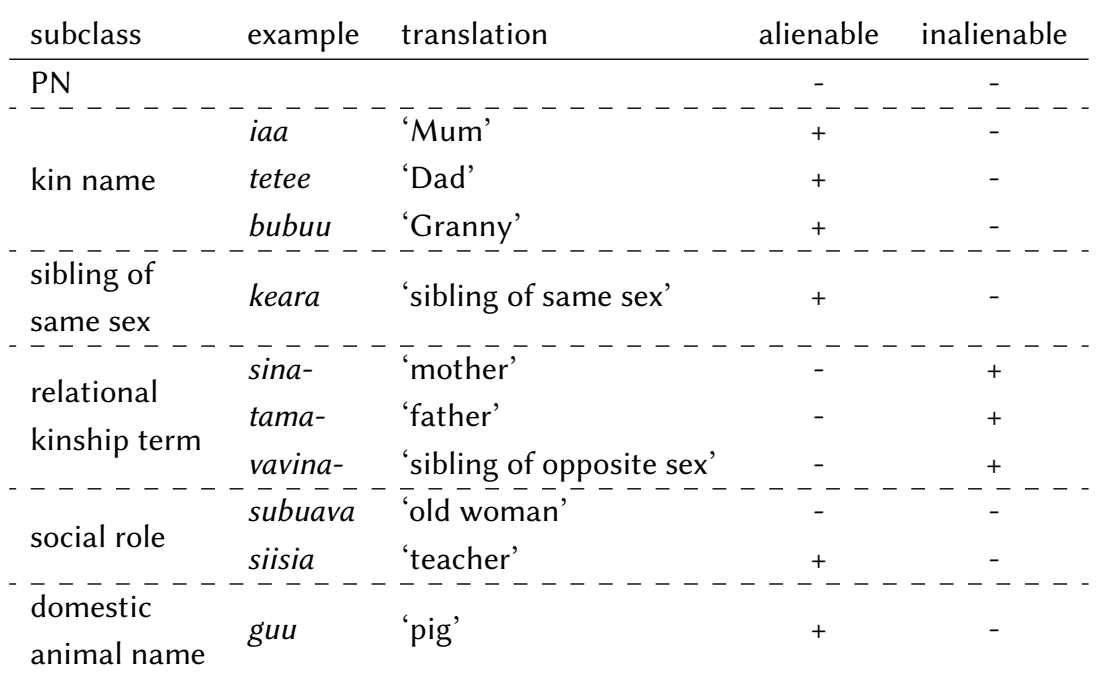

Table 7: Modification by possessor constructions

The kin name iaa 'Mum' is most frequently used by itself (92.8\%), in which case it refers to the speaker's mother, whereas the bound kinship term sina- 'mother' is never used with a first singular possessor. The distribution of third person singular possessors shows the opposite picture. Only $0.9 \%$ of all tokens of iaa 'Mum' are modified by a third person singular possessor, whereas with the kinship term sina- 'mother' it is $56 \%$.

Since iaa 'Mum' is mostly used without a possessor and only occurs in the singular, it can be classified as a noun of the individual type that through the incongruent determination by the alienable possessor construction undergoes a shift to the functional noun type without a change of noun class.

The alienable possessor construction is also found with the kinship term keara 'sibling of the same sex'. Grammatically this kinship term is not relational because it does not enter the inalienable possessive construction and may occur without any possessor. But the contexts in which it occurs provide sufficient evidence to affiliate it with the conceptually relational type of nouns. Firstly, it occurs in the special plural constructions of kinship terms which imply relation- 


\begin{tabular}{|c|c|c|c|c|c|c|}
\hline \multirow{2}{*}{$\begin{array}{l}\text { possessor } \\
\text { none }\end{array}$} & \multicolumn{3}{|c|}{ iaa 'Mum' } & \multicolumn{3}{|c|}{ sina- 'mother' } \\
\hline & $i a a$ & 'Mum' & 207 & - & 'mother' & - \\
\hline $1 \mathrm{sG}$ & iaa tenaa & my Mum’ & 9 & - & 'my mother' & - \\
\hline $2 \mathrm{sG}$ & iaa tean & ‘your Mum’ & 2 & sina-m-an & 'your mother' & 20 \\
\hline $3 s G$ & iaa teve & 'his/her Mum' & 2 & sina-na-e & 'his/her mother' & 178 \\
\hline 1PL.EX & iaa tenam & ‘our Mum’ & 1 & sina-ma-nam & 'our mothers' & 2 \\
\hline 1PL.IN & - & 'our Mum’ & 0 & sina-ra-ara & 'our mothers' & 3 \\
\hline $2 \mathrm{PL}$ & - & 'your Mum’ & 0 & sina-me-am & 'your mothers' & 8 \\
\hline 3PL & iaa teori & 'their Mum' & 1 & sina-ri-ori & 'their mothers' & 32 \\
\hline \multirow[t]{2}{*}{ NP } & iaa te $=\mathrm{NP}$ & 'NP's Mum' & 1 & $\sin a-n=\mathrm{NP}$ & 'NP's mother' & 76 \\
\hline & \multicolumn{2}{|c|}{$\begin{array}{l}\text { total number of tokens of } \\
\text { iaa 'Mum' }\end{array}$} & 223 & \multicolumn{2}{|c|}{$\begin{array}{l}\text { total number of tokens of } \\
\text { sina- 'mother' }\end{array}$} & 319 \\
\hline
\end{tabular}

Table 8: iaa 'Mum' and sina- 'mother' with possessor attributes

ality (see $\S 6.3, \S 6.4$ ), and secondly, if it is used in the singular without a possessor, it is modified by beera 'big' or rutaa 'small', which implies a relationship to a small or to a big brother or sister, respectively.

(29) $E$

keara

beera na piku-pikunana bona.

ART1.sG sibling.of.same.sex big TAM RED-lie 3SG.IPFV 4SG.PRON

'His elder brother lied to him.' (Auv_01R.009)

The grammatical relationality of kinship terms can be cancelled by the derelationalising suffix -na and a change of the noun class from the e-class to the o-class. Compare (26) with (30):

$$
\text { sina-na beera }
$$

ART3.SG- mother-DEREL ART3.SG big

'The mother is important.' (Vos_02R(Vos).083)

While in (26) the noun sina- 'mother' is a grammatically relational noun of the functional type, it is an abstract absolute term in (30) as it refers to the concept of mother in general or, put differently, to all mothers one can think of. ${ }^{8}$

\subsection{Possessive constructions of a-class nouns and type shifts}

Similar to the e-class nouns, the a-class nouns can be subclassified on the basis of whether they can be modified by a possessor or not, and those a-class nouns that take possessor attributes can be further divided into (1) those with inalienable, (2)

\footnotetext{
8 Note that the generic use of nouns is excluded in Löbner 2011.
} 
those with alienable and (3) those with both inalienable and alienable possessor constructions.

While place names are never used in possessive constructions, e. g. Тeapu 'Тeop Island', nouns denoting a part of a whole, including body parts, have inalienable possessors:

$a \quad$ kuri-na $=e$
ART2.sG hand-3sG.POSs =3sG.PRoN
'her hand' (Jan_01W 114)

As with relational e-class nouns, relational a-class nouns shift to the o-class, when they are used without a possessor. This happens, for example, in the context of cutting or eating a body part. Some of these words are bound forms and take the derelational suffix, but others are unbound and used without this suffix, as illustrated by the nouns kuri- 'hand' in (32) and kahoo 'head' in (2):

... bono meho kuri-na

ART3.SG other arm-DEREL

'(Materua, however, had eaten) the other arm.' (Aro_06E.58)

To conclude, the possessive constructions of a-class nouns show properties similar to those of e-class nouns:

- Names - in this case place names - are semantically unique and do not enter any possessive construction.

- Relational nouns, here typically denoting a part of a whole, may be used in non-relational constructions and then take the article of o-class nouns. But in contrast to the e-class nouns the loss of relationality is not consistently marked by the derelationalising suffix -na.

- The shift from the a-class to the o-class construction signifies the separation of a part from its whole, which may be interpreted as a downgrading from a higher to a lower degree of individuality.

\subsection{Possessive constructions of o-class nouns}

One of the most frequent o-class words is naono 1. 'tree, plant', 2. 'wood'. In its second sense 'wood' it is either used by itself or in an inalienable possessive construction:

O naono o kikisi, ...

ART3.SG wood ART3.SG strong

'The strong wood (is used for building houses).' (Joy_19W.072) 
(34)

O naono-na $=e \quad$ o asi-asi va-mataa.

ART3.SG wood-3SG.POSS =3SG.PRON ART3.SG RED-burn ADVR-good

'Its wood burns well.' (Sha_Aro_01E_trees.018)

In both the absolute and the relational construction it occurs with the same article o/bono.

\subsection{Summary}

All three noun classes contain grammatically relational nouns that occur in inalienable constructions, but may also be derelationalised. With e-class nouns, the loss of relationality is consistently marked by the suffix - na DEREL. In the a-class, some inherently relational nouns are marked when used as absolute terms but others are not; whereas in the o-class, inherently relational nouns remain unmarked when used as absolute terms. Derelationalised e- and a-class nouns are affiliated with the o-class, while o-class nouns remain in the o-class.

\begin{tabular}{llll} 
& semantic class & DEREL & noun class change \\
\hline e-class nouns & kinship term & + & e-class $>$ o-class \\
a-class nouns & part-of-a-whole term & $+/-$ & a-class $>$ o-class \\
o-class nouns & substance of an object & - & -
\end{tabular}

Table 9: Derelationalisation

The way relational e-class, a-class and o-class nouns behave differently with respect to possessive and absolute constructions suggests that they form a continuum with e-class nouns showing the highest degree of boundedness and o-class nouns the lowest.

\section{The expression of plurality}

Plurality in Teop can be expressed by:

1. cardinal numerals (see $\S 6.1$ );

2. the associative plural $^{9}$ article ere ART1.PL (see $§ 6.2$ );

3. the kinship plural marker $b a$ KIN.PL (see $\S 6.3$ );

4. the dyadic plural ${ }^{10}$ marker tom DYAD (see $\S 6.4$ );

\footnotetext{
9 See Corbett 2000: 101-111.

${ }^{10}$ See Evans 2006.
} 
5. the specific and non-specific a- and o-articles, which inversely mark the plural of o-class and a-class nouns (see Table 1 and $§ 6.5$ );

6. the plural marker maa PLM (§ 6.5).

The various kinds of plural marking clearly separate the e-class from the a- and the o-class, since ere ART1.PL, $b a$ KIN.PL and tom DYAD are exclusively used with e-class nouns, while the inverse plural marking by articles and the plural marker maa PLM are predominantly used with a- and o-class nouns.

\begin{tabular}{llll} 
plural marking & e-class & a-class & o-class \\
\hline associative plural marking & + & - & - \\
kinship plural marking & + & - & - \\
dyadic plural marking & + & - & - \\
plural marking by articles & $(+)$ & + & + \\
plural marker maa & $(+)$ & + & + \\
cardinal numerals & $(+)$ & + & +
\end{tabular}

Table 10: The expression of plurality

The e- and a-class nouns can be further subclassified on the basis of their plural marking properties. Apart from one exceptional example, the non-relational nonunique nouns of the e-class behave similarly to the sortal nouns of the a-class (see Table 11).

\begin{tabular}{|c|c|c|c|c|c|c|}
\hline class & Subclass & $\begin{array}{l}\mathrm{ART} 1 . \mathrm{PL} \\
\text { ere }\end{array}$ & $\begin{array}{l}\text { KIN.PL } \\
b a\end{array}$ & $\begin{array}{l}\text { DYAD } \\
\text { tom }\end{array}$ & $\begin{array}{l}\mathrm{ART} 2 / 3 . \mathrm{PL} \\
o / a\end{array}$ & $\begin{array}{l}\text { PLM } \\
\text { maa }\end{array}$ \\
\hline \multirow[t]{6}{*}{ e-class } & PN & + & - & - & - & - \\
\hline & kin name & + & - & - & - & - \\
\hline & $\begin{array}{l}\text { keara } \\
\text { 'same sex sibling' }\end{array}$ & - & + & + & - & - \\
\hline & kinship term & + & + & + & - & - \\
\hline & social role term & $(+)$ & - & - & + & + \\
\hline & domestic animal name & - & - & - & + & + \\
\hline \multirow[t]{2}{*}{ a-class } & toponyms & - & - & - & - & - \\
\hline & common noun & - & - & - & + & + \\
\hline o-class & common noun & - & - & - & + & + \\
\hline
\end{tabular}

Table 11: Subclassification of e-class, a-class and o-class nouns

In the following section, we will first deal with the cardinal numerals and then describe the data for the other ways of marking plurality. 


\subsection{Cardinal numerals}

Nouns of all classes can be modified by a cardinal numeral. With a- or o-class nouns, the cardinal numeral takes the respective singular article and may be modified by the determiner meha/meho 'other'. A-class nouns are modified by meha, o-class nouns by meho. Similar to meha/meho 'other', the cardinal numerals peha/peho 'one' and bua/buo 'two' agree with the head noun with respect to the noun class as illustrated in the following examples:

$$
m e=a \quad \text { meha bua otei }
$$

and $4=$ ART2.SG other two man

'and two other men' (Mor_01E.165)

(36) o meho buo sinivi

ART2.SG other two canoe

'two other canoes' (Eno_12W.013)

When a non-unique e-class noun is modified by a cardinal numeral or meha/meho 'other', the NP takes the very same form as a NP headed by an a-class noun:

$$
\begin{aligned}
& a \quad \text { meha bua keara te }=\text { naa } \\
& \text { ART2.sG other two sibling.of.same.sex PREP =1sG.PRON } \\
& \text { 'my two other brothers' (Rum_01E(Joy).010) }
\end{aligned}
$$
(38) A bua vavina-naa ere Maravaibo Unias.
ART2.sG two sibling.of.different.sex-1SG.PRON ART1.PL Maravai and2 Unias
'My two sisters are Maravai and Unias.' (Rum_01E(Joy).012)

This shift from the e-class to the a-class obviously correlates with a decrease in individuality, although keara 'sibling of the same sex' and vavina- 'sibling of the other sex' do not shift to another conceptual type, as they both remain nouns of the relational type with the features $[-U,+R]$.

\subsection{The associative plural}

The only plural form of person names is the associative plural construction ere $\mathrm{PN}$, which refers to a single person and his or her associates:

(39) Ere Rev. Shepherd

ART1.PL Rev. Shepherd

'Rev. Shepherd and his people (left Torokina ...)' (Pur_01E(Joy).030) 
In addition, the associative plural construction is found with kin names (40), kinship terms (41) and with coordinated constructions that contain a person name (42), a kin name or a kinship term (43). The associative plural construction of iaa 'Mum' and sina- 'mother' often refers to the mother and the aunts on the mother's side:

(40) ere iaa

ART1.PL Mum

'my Mum and aunties (do not speak like this, ...)' (Aro_14R.049)

(41)

.. benere sina-na $\quad=e$ bo tama-na =e

OBJ.ART1.PL mother-3SG.POSS =3SG.PRON and3 father-3SG.POSS =3SG.PRON '(and told) her Mum and Dad' (Skae_01W.100)

(42) ere Gaivaa bo Vasiri

ART1.PL PN and3 PN

'Gaivaa and Vasiri' (Sha_01E(Eno)G 007)

(43) Ere sina-na =e

ART1.PL mother-3sG.POSS =3SG.PRON

'Her mother and her aunts (would come now)' (Aro_14R.069)

One thing that all associative plural constructions have in common is that they refer to a group of people, but at the same time either single out a particular person who is accompanied by other unidentified people or refer to a couple of particular people. Searches for constructions of ere with the most common human a-class nouns moon 'woman' (1030 tokens), otei 'man' (857 tokens) and beiko 'child' (849 tokens) were unsuccessful.

The associative plural is a characteristic of highly individuated nouns. With the single exception of ere subuava bo Simura 'the old woman and Simura' (Sii_07W.099), e-class nouns that are semantically non-unique do not combine with the associative plural article.

\subsection{The plural marker ba}

The kinship plural marker $b a$ KIN.PL is used in NPs referring to a group of people who share the same kinship status with respect to some other people as, for instance, the fathers of the children of a village (44) or the brothers of a man (45): 
(44) A ba tama-ri =ori paakoarari bari. ART2.sg KIN.PL father-3PL.POSS =3PL.PRON TAM scold 3PL.OBJM 4PL.PRON 'Their fathers scolded them.' (Aro_10E.135)

(45)
a ba keara te =naa
ART2.sg KIN.PL sibling.of.same.seX PREP =1SG.PRON
'my brothers' (said by a man) (Mah_13R.587)

Similar to cardinal numerals, the plural marker $b a$ KIN.PL requires a change of e-class nouns to the a-class which indicates the loss of individuality and in (44) a shift from the functional conceptual type $[+\mathrm{U},+\mathrm{R}]$ to the relational type $[-\mathrm{U},+\mathrm{R}]$.

\subsection{The dyadic plural construction}

Kinship terms can combine with the dyadic marker tom. This marker indicates that the NP refers to both sides of a personal relationship. Thus tom sinana literally means 'persons in the mother-child relationship':

\section{bua tom sina-na}

ART2.SG two DYAD mother-DEREL

'(We will let) the mother and her child (go home ...)' (Mat_01R.128)

As illustrated by the preceding example, relational kinship terms are used in their absolute form marked by the derelational suffix $-n a$ and, similar to the plural marker $b a$ take the singular article of the a-class. The grammatically nonrelational noun keara 'sibling of the same sex' is used in its bare form:

(47) a bua tom keara

ART2.SG two DYAD same.sex.sibling

'two brothers' (Aro_03R.002)

Dyadic NPs are collective NPs and are always modified by an expression that quantifies the number of people in this dyadic relationship such as, for instance, the numeral bua 'two' or the plural marker maa (see § 6.5):

(48) $a=$

maa tom sina-na

ART2.SG= PLM DYAD mother-DEREL

'(Once upon a time there was) a mother with her children.' (Aro_06R.001)

(49) A bua si tom sina-na te =ara

ART two DIM DYAD mother-DEREL PREP =1INC

'our daughter and her child (lit. 'our two dear mother-child related (people)' (Mat_01E.145) 
In the dyadic construction the grammatically and conceptually relational noun $[+\mathrm{R}]$ becomes an absolute noun $[-\mathrm{R}]$ that can enter the relational alienable possessive construction:

$$
\left[\left[\text { a bua tom }[\text { sina- }]_{+R}-n a\right]_{-R} \text { teara }\right]_{+R}
$$

\subsection{Plural marking by articles and the plural marker maa}

Plural marking by articles and the plural marker maa signify plurality of discrete entities. Apart from cardinal numerals, they are the only plural form of a- and o-class nouns. The non-unique social role terms and domestic animal names of the e-class are treated like a-class nouns.

\begin{tabular}{l|l|l|l|l} 
class & \multicolumn{2}{|l|}{ singular article } & plural article & plural marker maa \\
\hline $\mathrm{e}$ & e siisia 'the/a teacher' & o siisia 'the teachers' & amaa siisia 'the teachers' \\
& e guu 'the/a pig' & o guu 'the pigs' & amaa guu 'the pigs' \\
$\mathrm{a}$ & a moon 'the/a woman' & o moon 'the women' & amaa moon 'the women' \\
$\mathrm{o}$ & o naono 'the/a tree' & a naono 'the trees' & amaa naono 'the trees'
\end{tabular}

Table 12: Plural marking by basic articles and the plural marker maa

The plural of a-class nouns is marked by the article o (or bono) and, inversely, the plural of o-class nouns by the article $a$ (or bona). ${ }^{11}$

The plural marker maa requires the article $a /$ bona irrespective of the noun's inherent class affiliation. With e-class nouns both kinds of plural marking only occur with the sortal type of nouns ${ }^{12}$.

Both types of plural marking are also found with a-class nouns of the relational type, but not with the relational o-class word naono 'wood'.

$$
\begin{aligned}
& \text {.. pa-re kosi bono paka-na = } . \\
& \text { 3PL-CONSEC TAM cut OBJ.ART2.PL leaf-3sG.POSS =3sG.PRON } \\
& \text { '(They cut the sago palm) and then they cut its leaves.' }
\end{aligned}
$$

$$
\begin{aligned}
& \text { me=ori kisi bona maa kuri-na = } \\
& \text { and4=3PL.PRON tie ART2.SG PLM hand-3SG.POSS =3SG.PRON } \\
& \text { 'and they tied his hands' (Viv_01E(Eno).054) }
\end{aligned}
$$

The difference between the two kinds of plural markings are not understood yet.

\footnotetext{
11 This kind of plural marking is called inverse plural marking; see Corbett (2000: 159-165) who also discusses the case of Teop.

12 There are two examples of unique kinship terms with maa PLM, but since they both occur in spontaneously narrated legends and were corrected by different editors in the edited versions, I consider them not as regular constructions (Aro_12R.134, Aro_12E(Joy).059, Jen_01R.070, Jen_01E(Eno).080).
} 


\section{Summary}

Teop has three noun classes that are formally distinguished by articles and called the e-, the a- and the o-classes. On the basis of their distribution in various types of possessive and plural constructions, e-class, a-class and o-class nouns can be further divided into subclasses which show some correlations with the conceptual types of individual, functional, relational and sortal nouns (see Table 13). For instance, the individual proper names of persons, kin names, kinship terms all belong to the e-class, whereas there are only a few sortal nouns in the e-class.

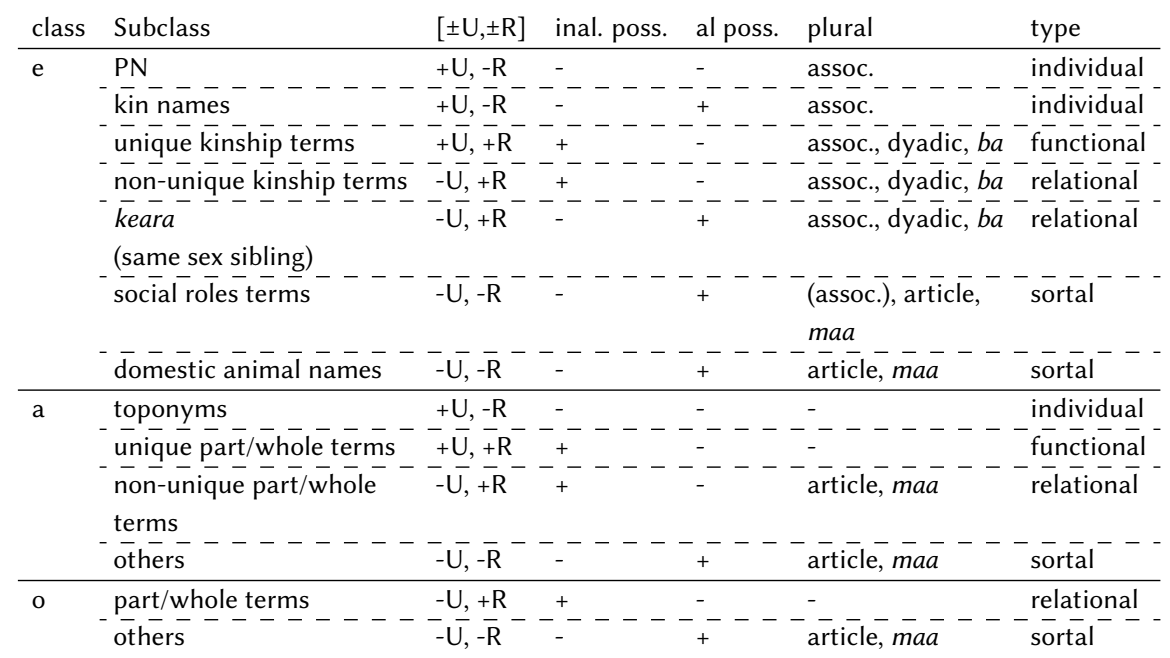

Table 13: Noun classes and subclasses

The o-class, on the other hand, contains no individual nouns and only a single relational noun, namely naono 'wood'. All other nouns in this class are sortal nouns (mostly plant names) or mass and abstract nouns which, however, have not been dealt with in this paper and are excluded by Löbner (2011).

The a-class is a kind of default class. It contains all nouns referring to human beings other than those of the e-class, all names of vertebrates, insects, spiders and crabs, all landmark terms, all nouns denoting food items, and all part-of-awhole terms irrespective of whether they belong to the functional or the relational type.

The mismatches between conceptual types and Teop noun classes are mostly due to the semantic feature [ \pm human] which plays a crucial role in the lexical and morphosyntactic structure of the Teop language and overrules the distinction between functional and relational types of nouns. 
The analysis of determination in Teop has shown the following correlations between noun class changes and conceptual type shifts:

1. Individual e-class nouns are regularly moved to the a-class in incongruent determinative constructions yielding a loss of uniqueness as in the constructions of predicative classification (see Table 15), existential negation (Table 16) and dyadic plurals (18).

2. If a sortal animal name of the a-class figures as the protagonist of a story and thus becomes unique, it is moved into the e-class (see Table 16).

3. If the functional and relational types of e-class and a-class nouns are derelationalised, they move from their lexically inherent class to the o-class (see Table 17).

But there are also three cases of type shifts that do not lead to a noun class change:

1. When nouns of the sortal type are determined by the anaphoric pronoun bona, they shift from the sortal to the individual, pragmatically unique type of noun, but do not undergo a noun class change (see Table 16).

2. The individual kin names, e.g. iaa 'Mum' can be determined by an alienable possessor, e.g. e iaa tenaa 'my Mum', without any noun class change, although they shift from the individual to the functional type of noun (see Table 17).

3. Determination by an alienable possessor also does not change the noun class of sortal nouns although it implies a shift from the sortal type to the individual, pragmatically unique type (see Table 17).

Finally, there are two changes of noun class affiliations that do not involve a type shift, although these changes may be interpreted as a decrease of individuality:

1. the marked indefiniteness construction of sortal e-class nouns (see Table 16) and

2. the quantificational determination of non-unique e-class nouns by cardinal numerals, the kinship plural marker $b a$ and the plural marker maa (see Table 18).

The vocative and locative constructions are characterised by the obligatory absence of an article, i. e. the loss of any noun class distinction (indicated by $>0$ in Table 14), which in the case of sortal nouns referring to persons and places implies a shift to the individual type of noun.

The conditions and the direction of the Teop noun class changes suggest that the noun classes and their subclasses form a scale of individuation with the proper 
names of the e-class representing the highest degree of individuality and the sortal o-class nouns the lowest, because a loss of uniqueness or relationality always results in a move from the e-class into the a- or the o-class, whereas a gain of uniqueness can lead to a movement from the a-class into the e-class.

\begin{tabular}{llll} 
construction & type shift & noun class change & reference \\
\hline vocative of individual nouns & - & e-class $>0^{13}$ & $\S 2.1(3)$ \\
vocative of sortal nouns & sortal $>$ individual & a-class $>0$ & $\S 2.1(4,5)$ \\
locative phrase of place names & - & a-class $>0$ & $\S 2.1(6,7)$ \\
locative of sortal noun & sortal $>$ individual & a-class $>0$ & $\$ 2.1(8,9)$
\end{tabular}

Table 14: Vocative and locative NPs

\begin{tabular}{llll} 
construction & type shift & noun class change & reference \\
\hline identification of individuals & - & - & $\S 2.2(10)$ \\
classification of individuals & individual > sortal & e-class > a-class & $\S 2.2(11)$ \\
classification of sortals & - & - & $\S 2.2(12$
\end{tabular}

Table 15: Predicative NPs

\begin{tabular}{llll} 
construction & type shift & noun class change & reference \\
\hline existential negation & individual > sortal & e-class > a-class & $\S 2.3(16,17)$ \\
anaphoric demonstrative & sortal > individual & - & $\S 4$, Tab. 5 \\
individuation of the protagonist & sortal > individual & a-class > e-class & \$4, Tab. 6 \\
indefiniteness of sortal nouns & - & e-class > a-class & §4 (22)
\end{tabular}

Table 16: Specific vs. non-specific, indefinite vs. definite anaphoric NPs

\begin{tabular}{llll} 
construction & type shift & noun class change & reference \\
\hline $\begin{array}{l}\text { alienable possession of } \\
\text { kin names } \\
\text { alienable possession of }\end{array}$ & sortal $>$ individual $>$ functional & - & $\S 5.1$, Table 8 \\
$\begin{array}{l}\text { sortal nouns } \\
\text { derelationalisation of }\end{array}$ & functional > absolute generic & e-class > o-class & $\S 5.1(26,30)$ \\
$\begin{array}{l}\text { kinship terms } \\
\text { derelationalisation of } \\
\text { part/whole terms }\end{array}$ & relational > sortal & a-class $>$ o-class & $\S 5.2(31,32)$
\end{tabular}

Table 17: Possessive constructions

$\overline{{ }^{13} 0}=$ loss of noun class distinction because of the absence of any article. 


\begin{tabular}{|c|c|c|c|}
\hline construction & type shift & noun class change & reference \\
\hline cardinal numerals with & - & e-class $>$ a-class & $\S 6.1(35-38)$ \\
\hline $\begin{array}{l}\text { relational and } \\
\text { sortal nouns }\end{array}$ & & & \\
\hline associative plural & - & - & $\S 6.2 .(39-43)$ \\
\hline \multirow[t]{2}{*}{ kinship plural } & functional > relational & e-class $>$ a-class & $\S 6.3(44)$ \\
\hline & - & e-class $>$ a-class & $\S 6.3(45)$ \\
\hline $\begin{array}{l}\text { dyadic plural } \\
\text { (derelationalisation) }\end{array}$ & $\begin{array}{l}\text { functional > absolute collective } \\
\text { relational }>\text { absolute collective }\end{array}$ & $\begin{array}{l}\text { e-class }>\text { a-class } \\
\text { e-class }>\text { a class }\end{array}$ & $\S 6.4(46-49)$ \\
\hline article marked plural & - & - & $\S 6.5$ \\
\hline plural marker maa & - & e-class $>$ a-class & $\S 6.5$ \\
\hline
\end{tabular}

Table 18: The expression of plurality

\section{Abbreviations}

1PL.EX 1st person plural exclusive

1PL.IN 1st person plural inclusive

1sG $\quad 1$ st person singular

2PL 2nd person plural

2SG 2nd person singular

3PL 3rd person plural

3SG 3rd person singular

4PL non-topical 4th person plural object pronoun used when the subject is a 3 rd person pronoun or NP

4SG non-topical 4th person singular object pronoun used when the subject is a 3rd person

ADVR adverbaliser, prefix that derives an adverb from a verb or an adjective

ANA anaphoric determiner

and1, and2, four distinct coordinating conjunctions

and3, and4

APP

applicative particle $n i$; transitivises intransitive verb complexes

ART1 basic article of the e-class nouns

ART2 basic article of the a-class nouns

ART3 basic article of the o-class nouns

CAUS causative prefix

COMP complementiser 


$\begin{array}{ll}\text { CONSEC } & \text { consecutive conjunction re 'then, so that' } \\ \text { DEM } & \text { demonstrative } \\ \text { DEREL } & \text { derelationalising suffix } \\ \text { DIM } & \text { diminutive particle } \\ \text { DYAD } & \text { dyadic quantifier, see } \S 6.4 \\ \text { GOAL } & \text { directional preposition vo } \\ \text { INDEF } & \text { indefiniteness marker } \\ \text { IPFV } & \text { imperfective aspect marker; inflects for person and num- } \\ & \text { ber } \\ \text { NEG ... NEG } & \text { disjunctive negation } \\ \text { NSPEC } & \text { non-specific (article) } \\ \text { OBJ.ART } & \text { object article } \\ \text { OBJM } & \text { object marker } \\ \text { PLM } & \text { plural marker } \\ \text { PN } & \text { proper name of person } \\ \text { POSS } & \text { possessive marker, inflects for person and number, see } \S 5 \\ \text { PREP } & \text { multiple purpose preposition, 'in', 'at', 'from', 'of', etc. } \\ \text { TAM } & \text { tense/aspect/mood marker } \\ \text { VOC } & \text { vocative particle } \\ \end{array}$

\section{Bibliography}

Corbett, G. G. 2000. Number. Cambridge: Cambridge University Press.

Evans, N. 2006. Dyadic constructions. In K. Brown (ed.), Encyclopaedia of language and linguistics, 24-28. Amsterdam: Elsevier 2nd edn.

Löbner, S. 2011. Concept types and determination. Fournal of Semantics 28(3). 279-333.

Mosel, U. 2010a. Ditransitive constructions and their alternatives in Teop. In A. Malchukov, M. Haspelmath \& B. Comrie (eds.), Studies in ditransitive constructions: a comparative handbook, 486-509. Berlin, New York: De Gruyter Mouton.

Mosel, U. 2010b. The fourth person in Teop. In J. Bowden, N. P. Himmelmann \& M. Ross (eds.), A journey through Austronesian and Papuan linguistic and cultural space: papers in honour of Andrew K. Pawley, 391-404. Canberra: The Australian National University: Pacific Linguistics.

Mosel, U. \& Even H. 1992. Samoan reference grammar. Oslo: Scandinavian Press. 
Type shifts and noun class changes under determination in Teop

Mosel, U. \& Y. Thiesen. 2007. The Teop language corpus. Accessed 2013.09.08. http://www.mpi.nl/DOBES/projects/teop.

Ross, M.. 1988. Proto-Oceanic and the Austronesian languages of Western Melanesia. Pacific Linguistics Series C - No. 98. Canberra: The Australian National University: Pacific Linguistics.

\section{Author}

Ulrike Mosel

ISFAS, General Linguistics

Kiel University

umosel@isfas.uni-kiel.de 
